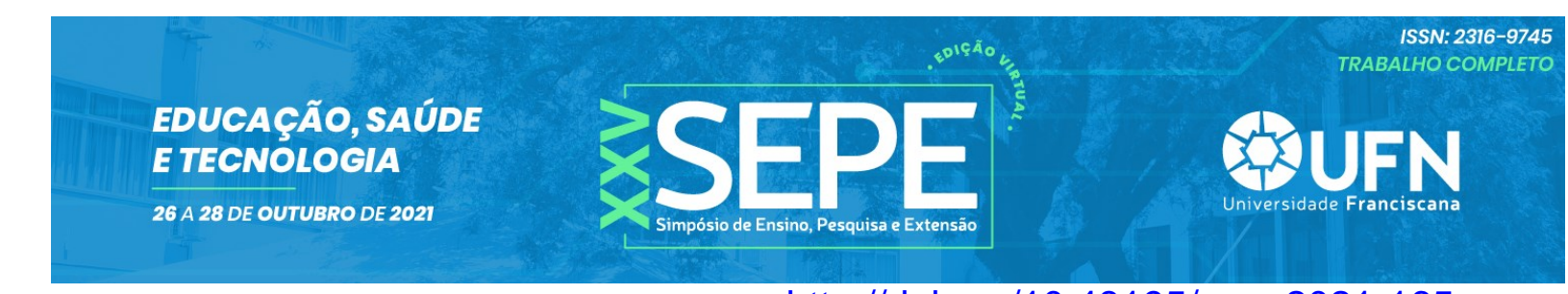

\title{
O ENSINO DE CIÊNCIAS NA INFÂNCIA: ALGUMAS CONSIDERAÇÕES A PARTIR DE UM LEVANTAMENTO BIBLIOGRÁFICO
}

\author{
Cícera Hilda Souza Santos ${ }^{1}$; Luis Sebastião Barbosa Bemme ${ }^{2}$
}

\section{RESUMO}

Essa comunicação tem por objetivo discutir o ensino de Ciências na Infância a partir de um levantamento bibliográfico. Tal preocu pação justifica-se na medida em que o ensino de Ciências, segundo a BNCC (2017), deve desenvolvero letramento científico, ou seja, a capacidade de compreender e interpretar o que está a sua volta. A pesquisa é de abordagem qualitativa e se caracteriza como um estudo documental. O processo de organização e intepretação dos dados se deu a partir de dois eixos de análise: I - Ensino de Ciências - Educação Infantil e II - Ensino de Ciências - Anos Iniciais. Tal ação é relevante para conhecer as ações de pesquisa que vêm sendo desenvolvidas nesse contexto. Como resultado, percebemos que na última década há poucos trabalhos voltados para o ensino de Ciências na Infância o que indica a carência de investigações nessa área.

Palavras-chave: Pesquisa bibliográfica; Educação Infantil; Anos Iniciais.

Eixo Temático: Educação, Cultura e Comunicação (ECC) - Comunicações breves/Revisões de literatura.

\section{INTRODUÇÃO}

Essa comunicação tem por objetivo discutir o ensino de Ciências na Infância a partir de um levantamento bibliográfico. Tal ação é relevante na medida em que é necessário conhecer as ações de pesquisa que vêm sendo desenvolvidas nesse contexto.

O ensino de Ciências na formação da criança, segundo a BNCC (2017), deve desenvolver o letramento científico, ou seja, a capacidade de compreender e interpretar o que está a sua volta no mundo, seja ele, natural, social e/ou tecnológico. Para que a partir disso, possam compreender, explicar e "transformá-lo com base nos aportes teóricos e processuais das ciências" (BNCC, 2017 p.321), fazendo intervenções conscientes, no mundo em que vivemos.

\footnotetext{
1 Acadêmica do Curso de Pedagogia da Universidade Franciscana - UFN. c.hilda@ufn.edu.br

2 Docente da Universidade Franciscana - UFN. luis.bemme@prof.ufn.edu.br
} 
Corroboram com essa ideia Arce, Silva e Varotto (2011) ao pontuarem que o ensino de Ciências designa um campo de conhecimento e uma série de atividades que tem como foco uma visão científica do mundo real. Nesse sentido a escola tem o dever de colocar a criança em contato com o conhecimento científico.

Nesse sentido as atividades experimentais e as questões investigativas devem estar de acordo com aspectos da vida dos alunos para que possam se constitu írem como problemas reais e desafiadores. Essas atividades devem oferecer condições para que os alunos possam levantar e testar ideias sobre fenômenos científicos que são expostos (ZANON; FREITAS, 2007).

No entanto, o ensino de Ciências na Infância, segundo Rosa; Perez e Drum (2007), não deve estar preocupado excessivamente com a precisão e sistematização dos conhecimentos, uma vez que a criança vai evoluindo no modo como constrói seus conceitos e significados, o ponto fundamental é que a criança esteja em contato com a ciência.

Para que essa aprendizagem ocorra, é extremamente necessário que o currículo de Ciências esteja organizado, por isso, a BNCC propõe três unidades temáticas, são elas: Matéria e energia; Vida e evolução; Terra e Universo (BRASIL, 2017).

A unidade temática Matéria e energia, compreende-se por um estu do de materiais e sua transformação, fontes e tipo de energia. Tendo o conhecimento da natureza da matéria e dos diversos usos da energia.

A segunda unidade temática, Vida e evolução, se volta para o estudo de to dos os seres vivos (incluindo os humanos), as características, como também as necessidades, a vida como vida como fenômeno natural e social.

E na última unidade temática, Terra e Universo, busca compreender as características da Terra, do Sol, da Lua e de, ainda, outros corpos celestes. Com a observação do céu, do planeta Terra e dos principais fenômenos celestes, possamos adentrar com maior riqueza de detalhes, as propriedades importantes para a preservação da vida na Terra.

Essa preocupação com o ensino de Ciências tem como base o fato de que a sociedade contemporânea está cada vez mais apoiada no desenvolvimento científico. Um exemplo disso é a pandemia atual de Covid - 19 que exigiu, em nível global, que os 
países se unissem para o desenvolvimento de vacinas e medicamentos.

Dessa forma, é relevante destacar que o ensino de Ciências da Natureza, devese apreender desde o infante. Pois percebemos, que cada vez mais as crianças têm a sua volta elementos da natu reza, materiais tecnológicos e manipuláveis no seu cotidiano, tornando assim, imprescindível uma formação formal voltada a uma melhor compreensão do que as cercam.

\section{METODOLOGIA}

A pesquisa é de abordagem qualitativa e se caracteriza como um estudo documental. Segundo GIL (2010), a pesquisa documental, corresponde a uma forma de pesquisa que utiliza fontes primárias, ou seja, dados e informações que ainda não foram tratadas científica ou analiticamente.

Essa forma de pesquisa, consiste em basicamente três etapas distintas: primeira, pré-análise, em que o pesquisador define quais perguntas pretende responder a cerca da análise dos dados. A segunda, é a fase de organização, a fim de facilitar a interpretação dos dados, principalmente quando a quantidade de dados for elevada. Já a terceira fase é a análise das informações, ou seja, com as fontes organizadas e classificadas é oportuno fazer a análise da coleta.

Para a coleta de dados na plataforma Scielo Brasil, foi aplicado o filtro Coleções - Brasil; Idioma - Português; Ano de publicação - 2010 até 2020; SciELO Áreas Temáticas - Ciências Humanas e Ciências Exatas e da Terra; Periódicos: Interface Comunicação, Saúde e Educação; Educar em Revista; História, Ciências, SaúdeManguinhos; Educação em Revista; Educação e Pesquisa; Educação \& Sociedade; Trabalho, Educação e Saúde; Ciência \& Educação (Bauru); Educação \& Realidade; Revista Brasileira de Educação; Cadernos de Pesquisa; Boletim do Museu de Paraense Emílio Goeldi. Ciências Humanas; Boletim de Educação Matemática; En saio Pesquisa em Educação em Ciências (Belo Horizonte); Revista Brasileira de Estudos Pedagógicos; Manuscrito.

O Quadro 01 apresenta o número de trabalhos encontrados por ano.

Quadro 01. Número de trabalhos encontrados por ano. 


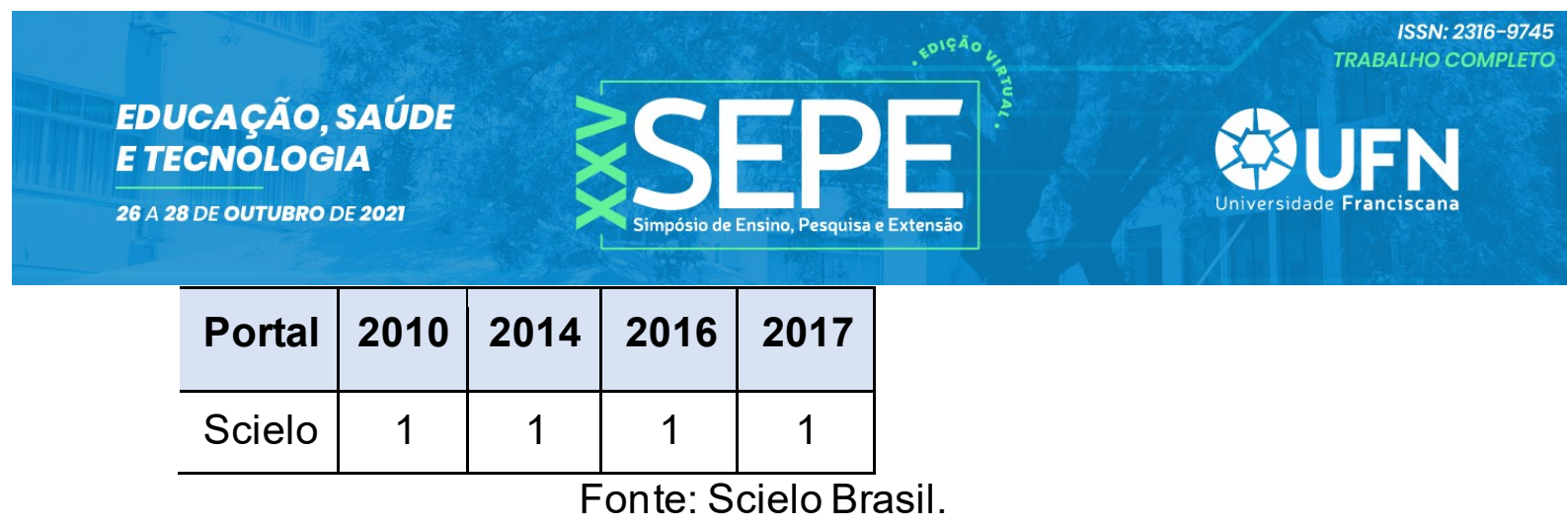

O processo de organização e intepretação dos dados se deu a partir de dois eixos de análise, são eles: eixo I - Ensino de Ciências - Educação Infantil e eixo II Ensino de Ciências - Anos Iniciais.

\section{RESULTADOS E DISCUSSÕES}

Os trabalhos selecionados estão organizados em dois eixos de acordo com o nível de ensino para o qual foram propostos. A seguir discutimos os trabalhos dos eixos construídos.

\section{Eixo I - Ensino de Ciências na Educação Infantil}

Nesse eixo, contempla a análise de um artigo intitulado, Aprendendo a ser afetado: contribuições para a educação em Ciências na Educação Infantil, de autoria de Coutinho, Goulart e Pereira, (2017). Tal trabalho teve como objetivo compreender os processos de aprendizagem de ciências por meio dos valores e dos conhecimentos realizados no contexto cultural do infante, ou seja, analisar os modos de participação das crianças em atividades de observação e exploração do ambiente.

Para essa análise, apresentou inicialmente a teoria ator-rede TAR de Latour, como referencial teórico-metodológico de análise das ordenações da infância. A partir de uma pesquisa colaborativa/formativa, utilizou como coleta de dados gravação em vídeo das atividades realizadas com as crianças como o principal material de análise. As falas das professoras nas reuniões e todo o material produzido pelas crianças - desenhos, fotos, cartazes configuraram-se como fontes secundárias para a triangulação dos dados.

Os principais resultados são que a análise de mundo pelas crianças pode ser realizada de modo sistemático, que envolvem observação, coleta, categorização de elementos humanos e não humanos. Ressaltando que as crianças como corpos que são capazes de ativamente explorar o mundo ao seu redor, isso pelas suas habilidades de serem afetadas pelos elementos humanos e não humanos. 
Eixo II - Ensino de Ciências nos Anos Iniciais

O segundo eixo de análise é composto por três trabalho que são discutidos a seguir.

O primeiro trabalho intitulado, Ensino de Ciências por investigação: uma estratégia pedagógica para promoção da alfabetização científica nos primeiros anos do Ensino Fundamental, escrito por Brito e Fireman (2016), teve como objetivo analisarse o ensino de ciências por investigação (referências teóricas e práticas), constitui-se como uma estratégia metodológica capaz da promoção da alfabetização científica nos primeiros anos do Ensino Fundamental.

Realizando uma pesquisa sob os fundamentos da abordagem qualitativa, caracterizando-se como um estudo de caso. Para a análise dos dados da presente pesquisa tomamos como referência a sequência didática De onde vem o arco-íris?, foi utilizado o uso de questionários com perguntas abertas, bem como o uso de gravações de áudio durante as aulas.

Como resultado, os autores enfatizam que o ensino de ciências por investigação possibilita uma metodologia de ensino satisfatória para alfabetizar cientificamente os alunos dos Anos Iniciais, visto que, quando são motivados a investigação, se comprometem com a atividade, desenvolvendo conteúdos conceituais.

No segundo trabalho, denominado Histórias em quadrinhos como recurso didático para o ensino do corpo humano em anos iniciais do Ensino Fundamental, das autoras Kawamoto e Campos (2014), teve como objetivo, elaborar e avaliar o gibi Corpo humano - uma história em quadrinhos, com conteúdos referentes à temática Corpo humano, contemplando os sistemas respiratório, digestivo, nervoso e circulatório.

Para a elaboração foram selecionados três livros didáticos: Coleção de Olho no futuro: $4^{a}$ série, Marinez Meneghello; Porta Aberta, $5^{\circ}$ Ano - Ciências Naturais, Sueli Fanizzi e Ângela Gil; o terceiro, Coleção Ciências para você: 4ª série, Márcia Santos Fonseca, Maria Hilda de Paiva Andrade, Marta Bouissou Morais, Maurício Bouissou Moraes. Já a avaliação do recurso gibi, foi realizada por uma turma do $5^{\circ}$ ano do Ensino Fundamental I, totalizando 18 estudantes, como também, pela professora regente da turma através de questionários. 
Concluindo que a HQs estimula o interesse dos alunos pela leitura e pelo conhecimento, é um recurso de uso prático e um excelente recurso complementar no processo de ensino aprendizagem.

O terceiro e último artigo, denominado Alfabetização científica no clube de Ciências do Ensino Fundamental: uma questão de inscrição, de autoria de Moisés Oliveira (2010), objetivou apresentar algu mas ponderações do processo da alfabetização científica nas atividades práticas de um clubinho de ciências.

A concepção teórico-metodológica valeu-se do conceito latou riano de inscrição e da perspectiva etnográfica não moderna. Com uma descrição narrativa da observação participante, os dados utilizados foram a tomada de notas, gravações, fotos e entrevistas.

Assim, conclui-se que a alfabetização científica é capaz de ser tomada como inscrição, ou seja, como registros, traços, meios que dão visibilidade ao conhecimento, valioso para os professores, que realmente seja capaz de conscientizar e emancipar.

\section{CONCLUSÃO}

A abordagem do ensino de Ciências voltado para a formação da criança, precisamente na Educação Infantil e no Ensino Fundamental, deve contribuir para o letramento científico, pois, compreendendo e interpretando o mundo à sua volta, seja natural, social e tecnológico, possam interagir com responsabilidade, tendo um novo olhar sobre o mundo que os cerca, fazendo escolhas e intervenções conscientes e "pautadas nos princípios da sustentabilidade e do bem comum" (BNCC, 2018).

Portanto, ainda surgem alguns questionamentos, acerca dessa temática do Ensino de Ciências na Infância, tais como: qual a real necessidade de uma criança aprender Ciências, conceitos tão complexos, para sua idade? ou ainda, por que ela, a criança, precisa saber disso, ela nem vai ser bióloga?

E por isso, é relevante destacar que o ensino de Ciências da Natureza, deve-se apreender desde a tenra idade. É somente direcionar um olhar minucioso para a sociedade contemporânea e percebemos, que vem crescendo cada vez mais o contato de crianças com os elementos da natureza, com materiais tecnológicos, que são manipuláveis no seu cotidiano, tornando assim, primordial uma formação voltada à compreensão do que as cercam. 
Assim, nosso trabalho apresentou os dados iniciais de uma pesquisa bibliográfica que indica uma número muito pequenos que trabalhos voltados para o ensino de Ciências na Infância, o que demonstra a necessidade de invetirmos em produções e publicações a cerca de experiências de ensino que considerem essa área do conhecimento.

\section{AGRADECIMENTOS}

Agradeço imensamente ao apoio da Pró-reitoria de Pós-Graduação e Pesquisa PROPESQ da Universidade Franciscana, UFN pelo apoio financeiro neste projeto. Ao meu orientador, Professor Luis Sebastião Barbosa Bemme pelas orientações e paciência.

\section{REFERÊNCIAS}

ARCE, Alessandra; SILVA, Debora A. S. M. da; VAROTTO, Michele. Ensinando ciências na educação infantil. Campinas: Alínea, 2011. 133 p.

BRASIL. Ministério da Educação. Base Nacional Comum Curricular. Brasília, 2018. Disponível em: http://basenacionalcomum.mec.gov.br/abase/\#fundamental/matematicano-ensino-fundamental-anos-iniciais-unidades-tematicas-objetos-de-conhecimento-ehabilidades Acesso em: 08 set. 2021.

BRITO, Liliane Oliveira de; FIREMAN, Elton Casado. ENSINO DE CIÊNCIAS POR INVESTIGAÇÃO: UMA ESTRATÉGIA PEDAGÓGICA PARA PROMOÇÃO DA ALFABETIZAÇÃO CIENTÍFICA NOS PRIMEIROS ANOS DO ENSINO FUNDAMENTAL. Ensaio Pesquisa em Educação em Ciências (Belo Horizonte) [online]. 2016, v. 18, n. 1, pp. 123-146. Disponível em: https://doi.org/10.1590/1983-21172016180107. Acesso em: 08 set. 2021. 
COUTINHO, Ângelo; GOULAR, Maria Inês Mafra; PEREIRA, Alexandre Fagundes. Aprendendo a ser afetado: contribuições para a educação em Ciências na Educação Infantil.

https://www.scielo.br/j/edur/a/nh5Y4j4HzJVZbBkR8NJRBtk/?lang=pt\&format=pdf Acesso em: 08 set. 2021.

GIL, A.C. Como elaborar projetos de pesquisa. 5 ed. São Paulo: Atlas, 2010.

KAWAMOTO, Elisa Mári; CAMPOS, Luciana Maria Lunardi. Histórias em quadrinhos como recurso didático para o ensino do corpo humano em anos iniciais do Ensino Fundamental. Ciência \& Educação (Bauru) [online]. 2014, v. 20, n. 1, pp. 147-158. Disponível em: https://doi.org/10.1590/1516-731320140010009. Acesso: 08 set. 2021.

OLIVEIRA, Moisés Alves de. ALFABETIZAÇÃO CIENTíFICA NO CLUBE DE CIÊNCIAS DO ENSINO FUNDAMENTAL: UMA QUESTÃO DE INSCRIÇÃO. Este trabalho foi originalmente apresentado no V Congresso Internacional de Educação. São Leopoldo, UNISINOS, 2007. Ensaio Pesquisa em Educação em Ciências (Belo Horizonte) [online]. 2010, v. 12, n. 2, pp. 11-26. Disponível em: https://doi.org/10.1590/198321172010120202. Acesso em: 08 set. 2021.

ROSA, C. W.; PEREZ, C. A. S.; DRUM, C. Ensino de física nas séries iniciais: concepções da prática docente. Investigações em Ensino de Ciências, v. 12, n. 3, p.357368, 2007.

VIEIRA, Renata Gonçalves; PEREIRA, Ademir de Souza; SERRA, Hiraldo. Apontamentos sobre o ensino de Ciências na Educação Infantil. Educação e Fronteiras, Dourados, v. 8, n. 24, p. 113-123, dez. 2018. ISSN 2237-258X. Disponível em: https://ojs.ufgd.edu.br/index.php/educacao/article/view/10261. Acesso em: 08 set. 2021.

ZANON, Dulcimeire Ap. Volante; FREITAS, Denise de. A aula de ciências nas séries iniciais do ensino fundamental: ações que favorecem a sua aprendizagem. Revista 
EDUCAÇÃO, SAÚDE

ETECNOLOGIA

26 A 28 DE OUTUBRO DE 2021

Ciências \& Cognição. Illha do Fundão.v. 10, mar. 2007. p. 93-103 Disponível em: Acesso em: 16 set. 2021. 